\title{
Effect of Mid-day Reduction of High Electrical Conductivity Treatment on the Yield and Quality of Greenhouse Cherry Tomato
}

\author{
Johann S. Buck ${ }^{1,2}$, Chieri Kubota ${ }^{1,3}$, and Merle Jensen ${ }^{1}$
}

ADDITIONAL INDEX WORDs. controlled environment, EC, premium grade, Lycopersicom esculentum, Solanum lycopersicum, sodium chloride

SUMMARY. Cherry tomato (Solanum lycopersicum var. cerasiforme) plants were grown hydroponically with three different regimes of electrical conductivity (EC) of the nutrient solution to develop an effective EC management method to enhance the fruit quality. The EC treatments examined were 1 ) continuous high EC $\left[4.7 \mathrm{dS} \cdot \mathrm{m}^{-1}\right.$ $(\mathrm{HE})], 2)$ continuous low EC $\left[2.8 \mathrm{dS} \cdot \mathrm{m}^{-1}(\mathrm{LE})\right]$, and 3 ) high EC combined with midday (1030-1530 HR) low EC [midday reduction of high EC (MDR)]. The research was conducted to obtain preliminary information on the effect of EC treatments on the yield and fruit quality for 15 weeks of harvest under semiarid greenhouse conditions. Harvested fruit were sorted to several quality grades, including the "premium" grade based on fruit size, color, and total soluble solids. The number of fruit per truss was significantly higher in cultivar L308 than in cultivar L907 and in the LE treatment than in the HE or MDR treatment. The fruit size decreased over time regardless of EC treatment and cultivar. Cumulative yield of 15 weeks was greater in the LE treatment $\left(26.3 \mathrm{~kg} \cdot \mathrm{m}^{-2}\right)$ than in the HE treatment $\left(22.1 \mathrm{~kg} \cdot \mathrm{m}^{-2}\right)$ for ' $\mathrm{L} 907$ ', and there were no significant differences between the three EC treatments for 'L308' $\left(24.1-28.1 \mathrm{~kg} \cdot \mathrm{m}^{-2}\right)$. The cumulative yield in the MDR treatment was similar to that in the LE treatment regardless of cultivar. When quality attributes such as total soluble solids concentration measured for randomly sampled fruit were considered, cumulative premium-grade yield was the greatest for the HE treatment $\left(12.9\right.$ or $\left.17.6 \mathrm{~kg} \cdot \mathrm{m}^{-2}\right)$ and was the smallest for the LE treatment $\left(1.4 \mathrm{or} 12.1 \mathrm{~kg} \cdot \mathrm{m}^{-2}\right)$, regardless of cultivar. The cumulative yield of premium-grade cherry tomatoes in the MDR treatment was not significantly different from that in the HE treatment for ' $\mathrm{L} 308$ ' but was $11 \%$ less than that in the HE treatment for 'L907'. Therefore, together with cultivar selection, the MDR treatment may be a potential alternative to a more commonly practiced continuously high EC treatment in semiarid greenhouses with limited environmental control capacity in which increasing the nutrient EC to increase quality is desired without significantly decreasing yield.

$\mathrm{T}$ The demand for cherry tomato has increased primarily from increased consumer preference of tomato quality parameters, such as appearance, flavor, and nutrition (Alarcon et al., 1994b). Total soluble solid concentration (TSS) has been used as a measure of flavor because of its simple measurement procedure using a handheld refractometer. High-quality cherry tomatoes with proper color, size, and high TSS can attain a premium price in the competitive fresh tomato market in North America. A common practice to

CEAC Paper Number D-125929-05-07.

${ }^{1}$ Department of Plant Sciences, The University of Arizona, 303 Forbes Building, Tucson, AZ 857210036

${ }^{2}$ Former Graduate Student; currently at University of Arkansas, Fayetteville, AR 72703

${ }^{3}$ Corresponding author. E-mail: ckubota@ag.arizona. edu. practiced in commercial greenhouses. This practice limits water flux into the fruit and thereby enhances the flavor components of the fruit. A common measure of the ion concentration of nutrient solution is electrical conductivity (EC) of the nutrient solution.

One disadvantage of increasing fruit TSS by increasing nutrient solution EC is reduction in fruit yields. Increasing the EC to greater than $2.3 \mathrm{dS} \cdot \mathrm{m}^{-1}$ has shown to increase TSS yet decrease tomato yield (Adams and Ho, 1989). The reduction in yield of tomatoes under high EC was attributed to smaller fruit weight and fewer fruit harvested (Adams, 1991; Adams and Holder, 1992). Dorais et al. (2001) reported in their review on influence of EC on greenhouse tomato yield and quality that tomato yields at 4.6, 8.0, and 12.0 $\mathrm{dS} \cdot \mathrm{m}^{-1}$ were lower compared with 2.3 $\mathrm{dS} \cdot \mathrm{m}^{-1}$. Yield at 4.6 and $8.0 \mathrm{dS} \cdot \mathrm{m}^{-1}$ was reduced because of fruit weight, whereas for $12.0 \mathrm{dS} \cdot \mathrm{m}^{-1}$, fruit number and weight were reduced. Another study reported yield reduction at EC from 2.3 to $5.1 \mathrm{dS} \cdot \mathrm{m}^{-1}$, whereas fruit quality has been improved at EC of 3.5 to $9.0 \mathrm{dS} \cdot \mathrm{m}^{-1}$ (Dorais et al., 2001). Yield and fruit weight of cultivars with smaller fruit size, such as cherry tomato, are less affected by increased nutrient solution EC than cultivars with larger fruit (Cuartero and Fernández-Munoz, 1999). Therefore, growing cultivars with smaller fruit size may be advantageous where water salinity is moderate or high (moderate to high EC). However, Alarcon et al. (1994a) showed that cherry tomato yield was reduced because of fewer in number and smaller in size fruit when EC was as high as $14 \mathrm{dS} \cdot \mathrm{m}^{-1}$, whereas fruit quality was increased with the

high EC.

\begin{tabular}{llll}
\hline $\begin{array}{l}\text { Units } \\
\text { To convert U.S. to SI, } \\
\text { multiply by }\end{array}$ & U.S. unit & SI unit & $\begin{array}{l}\text { To convert SI to U.S., } \\
\text { multiply by }\end{array}$ \\
\hline 0.3048 & $\mathrm{ft}$ & $\mathrm{m}$ & 3.2808 \\
0.0929 & $\mathrm{ft}^{2}$ & $\mathrm{~m}^{2}$ & 10.7639 \\
0.0283 & $\mathrm{ft}^{3}$ & $\mathrm{~m}^{3}$ & 35.3147 \\
3.7854 & gal & $\mathrm{L}$ & 0.2642 \\
2.54 & inch(es) & $\mathrm{cm}$ & 0.3937 \\
25.4 & inch $(\mathrm{es})$ & $\mathrm{mm}$ & 0.0394 \\
0.4536 & lb & $\mathrm{kg}$ & 2.2046 \\
4.8824 & $\mathrm{lb} / \mathrm{ft}^{2}$ & $\mathrm{~kg} \cdot \mathrm{m}^{-2}$ & 0.2048 \\
1 & meq/100 g & $\mathrm{cmol} \cdot \mathrm{kg}^{-1}$ & 1 \\
1 & $\mathrm{mmho} / \mathrm{cm}$ & $\mathrm{dS} \cdot \mathrm{m}^{-1}$ & 1 \\
1 & $\mathrm{ppm}$ & $\mathrm{mg} \cdot \mathrm{L}^{-1}$ & 1 \\
$\left({ }^{\circ} \mathrm{F}-32\right) \div 1.8$ & ${ }^{\circ} \mathrm{F}$ & ${ }^{\circ} \mathrm{C}$ & $\left(1.8 \times{ }^{\circ} \mathrm{C}\right)+32$ \\
& & &
\end{tabular}

achieve higher TSS in the fruit is to increase ion concentration in the nutrient solution, and therefore, to decrease $\psi_{\mathrm{S}}$ by increasing overall macronutrient concentration or by the addition of sodium chloride $(\mathrm{NaCl}$; Adams, 1991; Dorais et al., 2001, Krauss et al., 2006). The latter seems to be more economic and is therefore 
Another problem often observed in tomato grown under high EC is the increased incidence of blossom end rot (BER) caused by a reduction of calcium $\left(\mathrm{Ca}^{2+}\right)$ uptake by roots and increased resistance to xylem transport inside the fruit (Ho and Adams, 1989). In a study by Ho and Adams (1989), the effect of salinity on the accumulation of $\mathrm{Ca}^{2+}$ by tomato fruit was primarily an osmotic effect, reducing the uptake of $\mathrm{Ca}^{2+}$ by roots and translocation of $\mathrm{Ca}^{2+}$ in the xylem sap. However, increasing levels of only $\mathrm{Ca}^{2+}$ to the nutrient solution reduced the incidence of BER (Adams and Holder, 1992). Cherry tomatoes are considered more tolerant to BER caused by moderate water stress than are large-fruit-type tomatoes. Therefore, improving fruit quality by increasing the EC of the nutrient solution can be practiced with minimum constrains in cherrytype tomatoes compared with largefruit-type tomatoes.

Tomato quality is also influenced by light. A short-term net photosynthetic response of tomato plants grown with $8.4 \mathrm{dS} \cdot \mathrm{m}^{-1}$ EC resulted in reduced net photosynthetic rates only when light intensity exceeded $1000 \mu \mathrm{mol} \cdot \mathrm{m}^{-2} \cdot \mathrm{s}^{-1}$ photosynthetically active radiation $(P A R)$ for four different cultivars examined (Wu and Kubota, 2008). Light intensity in southwest Arizona can exceed 2000 $\mu \mathrm{mol} \cdot \mathrm{m}^{-2} \cdot \mathrm{s}^{-1} P A R$ in summer. Thus, light intensity inside the greenhouse could exceed $1000 \mu \mathrm{mol} \cdot \mathrm{m}^{-2} \cdot \mathrm{s}^{-1}$ when no shade screen is applied. In Mexico, a commercial cherry tomato production operation of a single-layer, polyethylene-covered greenhouse (with no shading nor evaporative cooling) adopted high EC nutrient solution on their cherry tomato plants to enhance the flavor of cherry tomatoes, but experienced large reductions in yield. Under semiarid greenhouse conditions, particularly when the solar radiation is intensive in summer, application of high EC to tomato plants is difficult, especially for the greenhouses with a limited capacity to control the environment.

Often, the midday greenhouse environment includes high light intensity, high temperature, and high vapor pressure deficit (VPD), all of which are factors enhancing the plant transpiration rate. Therefore, tomato plants under midday conditions in the summer, particularly in semiarid regions, including southern Arizona and northern Mexico, are expected to be grown under high water stress conditions. Li et al. (2001) demonstrated that fruit yield and quality were affected by root zone (i.e., EC) and aerial environment (i.e., VPD). The high VPD, a condition causing potentially high transpiration, decreased the fruit yield further than low VPD (Li et al., 2001). One resolution to avoid the midday stress under the combination of high EC and high light intensity would be to introduce a shade screen during the midday, although this method will reduce the $P A R$ and therefore plant photosynthetic rates. Another possible solution is to apply low EC during the midday to mitigate the high water stress on the tomato plants, and this strategy may retain the high photosynthetic rate and yields while maintaining the high TSS.

Provided at the appropriate time, a short-term increase in high EC levels can be used to improve the quality of tomato fruit with less reduction in yield than continuous high EC (van Ieperen, 1996). We could identify a limited number of reports on the effect of day/night EC levels on fruit quality and yield of any tomato type. Adams and Ho (1989) studied the effects on continuous and fluctuating EC levels on tomato fruit, where they examined high daytime EC $\left(8 \mathrm{dS} \cdot \mathrm{m}^{-1}\right)$ combined with low nighttime EC $\left(3 \mathrm{dS} \cdot \mathrm{m}^{-1}\right)$ compared with several constant EC levels (3, 5.5 , and $\left.8 \mathrm{dS} \cdot \mathrm{m}^{-1}\right)$. They found that the yield of Class 1 fruit of the fluctuating EC treatment was similar to that of tomato grown with 3 and $5.5 \mathrm{dS} \cdot \mathrm{m}^{-1}$ treatments and sugar concentration similar to that with 8 $\mathrm{d} S \cdot \mathrm{m}^{-1}$ treatment. However, the sugar concentration was unaffected by EC treatment when based on a gram per fruit or gram per dry matter, suggesting that the increase in sugar observed under the fluctuation EC treatment and $8 \mathrm{dS} \cdot \mathrm{m}^{-1}$ treatment was a concentration effect. In Santamaria et al. (2004), the effects of diurnal fluctuation in nutrient EC were studied and it was found that a 2 $\mathrm{dS} \cdot \mathrm{m}^{-1}$ daytime EC combined with 6 $\mathrm{dS} \cdot \mathrm{m}^{-1}$ nighttime EC level did not affect total yield, fruit number, fruit weight, or plant water consumption.
The TSS of the cherry tomato 'Naomi' was significantly increased at $2 / 6 \mathrm{dS} \cdot \mathrm{m}^{-1}$ day/nighttime EC level versus the continuous $2 \mathrm{dS} \cdot \mathrm{m}^{-1}$ EC treatment.

Our objective in this study was to determine the effects of three different regimes of EC treatments (high EC, low EC, and a combination of high EC with midday low EC) on the fruit yield and quality of two cherry tomato cultivars over time.

\section{Materials and methods}

Cultivars AND Plant growth condiTIONS. The experiment was completed during April through Oct. 2003. 'L308' and 'L907' cherry tomatoes were seeded on 1 Apr. 2003 $[0 \mathrm{~d}$ after seeding (DAS) $]$ in $4 \times 4 \times$ $4-\mathrm{cm}$ rockwool cubes and were then covered with a thin layer of vermiculite. The trays were kept on a nonheated misting bench inside a greenhouse and were sprayed with water through misting nozzles for a duration of $12 \mathrm{~s}$ every $16 \mathrm{~min}$. Once cotyledons were fully expanded, seedlings were fertigated with a halfstrength, modified Hoagland's solution with an EC of $1.3 \mathrm{dS} \cdot \mathrm{m}^{-1}$. On 18 DAS, uniform seedlings were transplanted into individual $10 \times 10 \times$ $7-\mathrm{cm}$ rockwool cubes. On 29 DAS, when the seedlings reached a stage of three to four true leaves, the apical shoots were removed above the second true leaf from the bottom to induce two axillary shoots for each seedling.

A $24 \times 48$-ft, north-south oriented, A-frame compartment located within a polycarbonate-glazed gutter connected greenhouse structure at The University of Arizona Campus Agriculture Center (Tucson) was used for the experiment. The greenhouse was equipped with a fan-andpad evaporative cooling system. The fertigation system was a top-fed/ drip-irrigated system and drainage was properly disposed of by creating a gutter system placed along each row guiding the drainage to the sanitary sewer. Plants were grown in bags containing coconut coir as substrate in north-south oriented rows. Styrofoam blocks $15 \mathrm{~cm}$ high were placed under the bags to elevate the bags and to assist with drainage of the nutrient solution. Each white plastic bag was $81 \times 20 \mathrm{~cm}$ and was filled with 
$\approx 0.02 \mathrm{~m}^{3}$ of coconut coir supplied by Germinasa (Zapopan, Mexico).

On 44 DAS, three seedlings with two axillary shoots (or heads) were transplanted in each coconut coir bag, after rinsing the coir with water until the leachate EC decreased to $3.3 \mathrm{dS} \cdot \mathrm{m}^{-1}$. Planting density was 2.2 plants $/ \mathrm{m}^{2}$ or 4.4 heads $/ \mathrm{m}^{2}$. Plant canopy height was maintained at 2.1 to $2.3 \mathrm{~m}$ above the ground by leaning the plants in a north to south direction once the plant canopy reached the support wire height.

A programmable timer (Sterling 8 sprinkler controller; Superior Controls Co., Valencia, CA) was used to schedule and control the fertigation cycles and the midday reduction of EC. The drip fertigation system was designed to deliver $\approx 100$ mL of nutrient solution per plant using pressurecompensated emitters (flow rate $=$ $\left.2 \mathrm{~L} \cdot \mathrm{h}^{-1}\right)$. Capillary tubing ( $3 \mathrm{~mm}$ i.d.) cut to a $48-\mathrm{cm}$ length was placed onto emitters and was supported by stabilizer pegs to deliver the nutrient solution to each plant. The irrigation frequency was once every 15 to 30 min from 0600 to 1700 or $1800 \mathrm{HR}$ for duration of $3 \mathrm{~min}$, depending on the plant transpiration demands and outside climate conditions. Day and night air temperature set points to activate evaporative cooling system and overhead heating system were 24 and $18{ }^{\circ} \mathrm{C}$, respectively.

Treatment conditions. During the first 2 weeks in the greenhouse, seedlings were grown under the low EC $\left(2.8 \mathrm{dS} \cdot \mathrm{m}^{-1}\right)$ nutrient solution. After 2 weeks in the greenhouse (29 May 2003), plants were subjected to the three EC treatments. These treatments consisted of a conventional low EC $\left(2.8 \mathrm{dS} \cdot \mathrm{m}^{-1}\right)$ treatment (LE), high EC $\left(4.7 \mathrm{dS} \cdot \mathrm{m}^{-1}\right)$ treatment (HE), and midday reduction of high EC treatment (MDR). The MDR treatment was achieved by fertigating the plants with the high EC nutrient solution in the morning until $1030 \mathrm{HR}$, and then replacing it with the low EC nutrient solution until 1500 or $1530 \mathrm{HR}$. These timings were decided based on the light intensity inside the greenhouse and also the low EC application time limited to $\approx 40 \%$ of the total feeding time (40\% irrigation with low EC and $60 \%$ with high EC). Thereafter, the plants were fertigated again with the high EC nutrient solution until 1700 or $1800 \mathrm{HR}$, depending on when the feeding cycle ended. The basal nutrient solution of the three treatments was a modified Hoagland's solution containing the following elements (in $\mathrm{mg} \cdot \mathrm{L}^{-1}$ ): 142 nitrogen (all in nitrate form), 65 phosphorus, 374 potassium, 133 sulfur, 150 calcium, 66 magnesium, 112 chlorine, 0.4 boron, 2.0 iron, 0.6 manganese, 0.3 zinc, 0.05 copper, 0.05 molybdenum, and 0.42 sodium. The high EC solution was obtained by adding $957 \mathrm{mg} \cdot \mathrm{L}^{-1} \mathrm{NaCl}$ and $32 \mathrm{mg} \cdot \mathrm{L}^{-1}$ calcium chloride $\left(\mathrm{CaCl}_{2}\right)$.

To avoid the excessive increase of EC in the plant root zone, we maintained the efflux solution (or drainage) EC for the HE treatment at a target of 7.0 to $7.5 \mathrm{dS} \cdot \mathrm{m}^{-1}$, adjusted by manipulating irrigation frequency and the dilution rate of inflow EC. There was not a set target drainage EC level for the LE or MDR treatments. The target minimum percent drainage of EC nutrient solution was $40 \%$, a widely practiced value in hydroponic tomato production, and the percentage was adjusted by manipulating irrigation frequency via the irrigation timer.

Measurements and data COLLECTIONS. Volume, $\mathrm{pH}$, and EC of the inflow and efflux nutrient solutions to plants and drained from the coconut coir bags were recorded daily using a simple lysimeter set for each replication (nine lysimeters in total). Hand-held EC and $\mathrm{pH}$ meters (Hanna Instruments, Woonsocket, RI) were used and calibrated weekly.

Environmental data collected inside the greenhouse included photosynthetic photon flux $(P P F)$, air temperature, relative humidity $(\mathrm{RH})$, and atmospheric VPD. All environmental parameter sensors were connected to a data logger (CR-10X; Campbell Scientific, Logan, UT). The PPF was measured using a LI190SA Quantum Sensor (LI-COR, Lincoln, NE) placed over the plant canopy. RH and VPD were computed by measuring wet and dry bulb temperatures using 18-gauge Type-T thermocouples placed inside an aspirated, radiation shield box in the central location of the greenhouse.

Fruit trusses were harvested based on overall fruit color once every week for 15 consecutive weeks. A harvestable truss was one in which at least $80 \%$ of the fruit on a truss were in red ripeness stage. Fruit were weighed and graded immediately after the harvest and quality measurements were taken within $24 \mathrm{~h}$. Individual fruit on the vine were graded into one of six quality grades: 1) "premium," 2) standard "cherry," 3) "large," 4) "shattered," 5) "cracked," and 6) "green" fruit, following an industry standard of grading cluster cherry tomatoes. "Premium" was the most valuable and desired grade and "cracked" and "green" grades were not marketable. There were several attributes that make up the premium grade of cluster cherry tomatoes according to the quality standards introduced in industry. These are size, color, and TSS. Fruit that did not meet these requirements were removed from the truss. Fruit had to be larger than $2.2 \mathrm{~cm}$ and less than $3.8 \mathrm{~cm}$ in diameter. Fruit larger than $3.8 \mathrm{~cm}$ were separated from the truss and placed in the large grade. The target color for premium grade is solid red, and deep red fruit, which tended to be soft, and less ripened fruit were also removed. The overall TSS had to meet the minimum of $6.5 \%$ to be considered premium. Fruit that were within the size requirements, but did not meet color requirements were cherry grade. All fruit that dehisced from the pedicel during harvest or during the removal of the trusses from their containers during the weighing process were categorized as shattered. Any and all fruit except green that were cracked were placed into the cracked grade. In the present report, we focus on the yield and quality of premium fruit as affected by EC treatment and cultivar, although gross weight, gross number of trusses, number of fruit in each grade, and their weight were also measured and recorded.

The TSS was measured for all fruit of the truss (TSS) after removing fruit outside the premium size and color requirements, using a hand refractometer (N-20E; ATAGO USA, Bellevue, WA), and those values were then converted to those at standard temperature conditions of $20{ }^{\circ} \mathrm{C}$. Sample fruit were removed and ground for $\approx 2$ to $3 \mathrm{~s}$ to extract the juice. TSS measurements were conducted for one truss randomly sampled from all trusses harvested from each replication of each treatment and cultivar. If the average TSS 
of sampled trusses exceeded $6.5 \%$ and met the other criteria (size and color) on the same harvest date, then all fruit within the size and color requirements harvested from the replication were considered as premium grade.

Data collected throughout the experiment were analyzed using JMP IN software (SAS Institute, Cary, NC). The experimental design was factorial (treatment and cultivar). Each EC treatment was replicated three times, using latin square design inside the greenhouse. The two cultivars were randomly distributed within each replication. Two coconut coir bags (experimental unit) supporting six plants or 12 heads per bag were placed in each replication per cultivar (36 bags or 216 heads in total). Treatment significances and mean separation were analyzed by analysis of variance (ANOVA) and least significant difference (LSD) test, respectively. Factors included in factorial analysis were harvest week, cultivar, and treatment.

\section{Results and discussion}

Average day (0600-1800 HR) and night (1800-0600 HR) air temperatures inside the greenhouse during experiment (May through Oct. $2003)$ were $27.0 \pm 3.8^{\circ} \mathrm{C}$ and $23.0 \pm$ $2.0{ }^{\circ} \mathrm{C}$, respectively. The average day and night RH inside the greenhouse during the experiment was $72.0 \% \pm 5.1 \%$ and $84.0 \% \pm 1.7 \%$, respectively. The average day and night atmospheric VPD inside the greenhouse was $0.36 \pm 0.27 \mathrm{kPa}$ and $0.28 \pm 0.20 \mathrm{kPa}$, respectively. The average daily $P P F$ inside the greenhouse was $33 \pm 9 \mathrm{~mol} \cdot \mathrm{m}^{-2} \cdot \mathrm{d}^{-1}$. The average EC of the influx nutrient solution collected daily during the experiment (May through Oct. 2003 ) was $2.8 \pm 0.02 \mathrm{dS} \cdot \mathrm{m}^{-1}, 3.8 \pm$ $0.02 \mathrm{dS} \cdot \mathrm{m}^{-1}$, and $4.7 \pm 0.3 \mathrm{dS} \cdot \mathrm{m}^{-1}$ for the LE, MDR, and HE treatments, respectively. The average EC of the efflux nutrient solution from the substrate bags for the LE, MDR and $\mathrm{HE}$ treatments was $3.6 \pm 0.04$ $\mathrm{dS} \cdot \mathrm{m}^{-1}, 5.1 \pm 0.04 \mathrm{dS} \cdot \mathrm{m}^{-1}$, and $6.6 \pm$ $0.06 \mathrm{dS} \cdot \mathrm{m}^{-1}$, respectively. The time needed to adjust the EC from high to low EC and vice versa in the MDR treatment was minimal. We were able to achieve the desired EC within 30 min or two consecutive fertigations (at 15-min intervals) of changing EC levels. During most experimental periods, the fertigation frequency remained at $15 \mathrm{~min}$ from $0600 \mathrm{HR}$ to 1700 or $1800 \mathrm{HR}$. Under such frequent fertigation, we do not believe that physical and chemical properties of the substrate became a major factor affecting the EC of the root zone. Average cation exchange capacity of coconut coir of different sources was 39 to $60 \mathrm{meq} / 100 \mathrm{~g}$, which is lower than that of commonly used sphagnum peat (Evans et al., 1996). The initial EC of many coconut coir substrates may be high, but the general range for coconut coir EC is 0.3 to $2.9 \mathrm{dS} \cdot \mathrm{m}^{-1}$ (Evans et al., 1996), affected by many factors. Some facilities soak the raw coconut husk in highly saline water before grinding, which contributes to high potassium, sodium, and chloride levels. Also, many plantations fertilize the crop with potassium chloride (KCl) and $\mathrm{NaCl}$ (Evans et al., 1996). Finally, coconuts are semihalophytes and absorb salts, which are then translocated to the developing fruit (Jeganathan, 1992), which contributes to the high salt concentrations. In our experiment, the difference in influx and efflux nutrient solution was as low as $0.8 \mathrm{dS} \cdot \mathrm{m}^{-1}$ for the LE treatment, and therefore the influence of coconut coir EC was considered negligible under the present conditions.

The average $\mathrm{pH}$ of the influx nutrient solution was $6.3 \pm 0.01$ regardless of treatment. The average $\mathrm{pH}$ of the efflux nutrient solution for the $\mathrm{LE}, \mathrm{MDR}$ and $\mathrm{HE}$ treatments was $6.3 \pm 0.02,6.3 \pm 0.02$, and $6.3 \pm$ 0.03 , respectively. The percentage of drainage (volume ratio of efflux and influx nutrient solution) was maintained at $40 \%$ or greater during most of the experiment. The net photosynthetic rate, transpiration, and leaf conductance measured using a leaf chamber were not significantly affected by EC treatment or cultivar (data not shown), suggesting that the plants were acclimated to the moderate water stress caused by the $\mathrm{HE}$ or MDR treatment. Osmotic adjustment (decreasing $\psi_{S}$ as well as an increase in turgor potential) of cherry tomato leaf were observed under 7.23 and $12.61 \mathrm{dS} \cdot \mathrm{m}^{-1} \mathrm{EC}$ by increasing inorganic solute concentrations in leaf greater than those under 1.45 $\mathrm{dS} \cdot \mathrm{m}^{-1}$ EC (Alarcon et al., 1994b).

Eight weeks after transplanting (9 July 2003) in the greenhouse, the first cherry tomato fruit trusses were harvested for both cultivars. The cumulative number of trusses harvested per plant for 15 weeks was significantly affected by cultivar and EC without significant interaction (Table 1). There were more trusses produced in 'L308' than 'L907' and in the HE or MDR treatment than in the LE treatment, although the difference between two cultivars or EC treatments was small (0.7-0.8 trusses for 15 weeks). In van Ieperen (1996), the number of trusses decreased with time in plants under $9 \mathrm{dS} \cdot \mathrm{m}^{-1}$ for 140 d. The high EC examined by van Ieperen (1996) was $9 \mathrm{dS} \cdot \mathrm{m}^{-1}$, whereas our EC never exceeded 8 $\mathrm{dS} \cdot \mathrm{m}^{-1}$ in the HE treatment and 6 $\mathrm{dS} \cdot \mathrm{m}^{-1}$ in the MDR treatment. According to Cuatero and Fernández-Muñoz (1999), the number of trusses per plant was reduced only with highly saline conditions and with a long salinization period, and otherwise, the characteristic seems to have little response to high EC. In the present experiment, the weekly number of truss harvested per plant increased until around 16 weeks after transplant and then decreased, regardless of EC for both cultivars (data not shown), suggesting that the number of trusses in the present experiment was more responsive to plant physiological age or seasonal change in greenhouse environments.

Table 1. Cumulative number of trusses (all grades) of cherry tomato fruit for 15 weeks of harvest and weekly number of fruit per truss (all grades) as affected by cultivar and EC treatment.

\begin{tabular}{|c|c|c|}
\hline Factors $^{\mathrm{z}}$ & $\begin{array}{c}\text { Cumulative } \\
\text { trusses } \\
\text { (no./plant) }^{\mathrm{y}}\end{array}$ & $\begin{array}{c}\text { Weekly } \\
\text { fruit } \\
\text { (no./truss) } \\
\end{array}$ \\
\hline \multicolumn{3}{|l|}{ Cultivar } \\
\hline L308 & $19.7^{a}$ & $17.0^{\mathrm{a}}$ \\
\hline L907 & $18.9^{\mathrm{b}}$ & $13.8^{\mathrm{b}}$ \\
\hline \multicolumn{3}{|l|}{$\mathrm{EC}$} \\
\hline $\mathrm{HE}$ & $19.6^{\mathrm{A}}$ & $15.1^{\mathrm{B}}$ \\
\hline $\mathrm{LE}$ & $18.8^{\mathrm{B}}$ & $16.1^{\mathrm{A}}$ \\
\hline MDR & $19.5^{\mathrm{A}}$ & $15.0^{\mathrm{B}}$ \\
\hline \multicolumn{3}{|l|}{ Cultivar } \\
\hline$\times \mathrm{EC}^{\mathrm{x}}$ & $P=0.16$ & $P=0.45$ \\
\hline 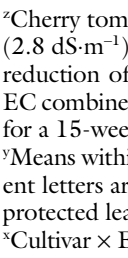 & $\begin{array}{l}\text { plants were grow } \\
\text { igh EC }[\mathrm{HE}(4.7 \\
\text { gh EC treatment } \\
\text { ith high EC)], an } \\
\text { eriod }\left(1 \mathrm{dS} \cdot \mathrm{m}^{-1}=\right. \\
\text { le same column fo } \\
\text { gnificantly differe }\end{array}$ & $\begin{array}{l}\text { Inder low EC [LE } \\
\left.\left.S \cdot \mathrm{m}^{-1}\right)\right] \text {, or midday } \\
\text { IDR (midday low } \\
\text { ruit were harvested } \\
\text { mmho/cm). } \\
\text { owed by the differ- } \\
\text { from an ANOVA- } \\
\text { test at } P<0.05 \text {. } \\
\text { by ANOVA. }\end{array}$ \\
\hline
\end{tabular}


'L308' plants produced 25\% more fruit per truss than did 'L907' plants (Table 1). A small (7\%) reduction in number of fruit per truss was observed in the HE or MDR treatment compared with that in the LE treatment. We found conflicting results on number of fruit as affected by EC in the nutrient solution. Santamaria et al. (2004) reported that EC treatment $\left(2\right.$ and $\left.6 \mathrm{dS} \cdot \mathrm{m}^{-1}\right)$ did not significantly affect the number of cherry tomato fruit harvested. Alarcon et al. (1994a) found a $40 \%$ to $50 \%$ reduction in number of cherry tomato fruit per plant when grown under a EC as high as $14 \mathrm{dS} \cdot \mathrm{m}^{-1}$.

The treatment $\times$ cultivar $\times$ week interaction was significant $(P=0.04)$ for fruit weight (fresh weight per fruit; Fig. 1). Regardless of EC treatment, both cultivars experienced a steady decline of the fruit weight over time. The final fruit weight on the 15th harvest week or 22 weeks after transplant was 0.0106 to $0.0119 \mathrm{~kg}$ less than those at the first harvest week, regardless of EC treatment or cultivar. 'L907' produced larger fruit than 'L308'. The overall fruit weight in the LE treatment was $11 \%$ greater than that in the HE treatment, but not significantly different from that in the MDR treatment, regardless of cultivar. A $10 \%$ reduction in fruit weight was reportedly observed with 5 to $6 \mathrm{dS} \cdot \mathrm{m}^{-1}$, a $30 \%$ reduction with $8 \mathrm{dS} \cdot \mathrm{m}^{-1}$, and a $40 \%$ reduction with higher EC (Cuartero and FernándezMunoz, 1999; González-Fernández

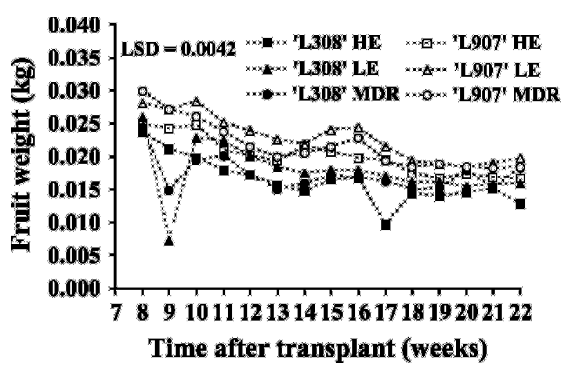

Fig. 1. The fruit weight of cherry tomato harvested over a 15-week period. The cultivar $\times$ EC treatment $\times$ week interaction was significant $(P=$ 0.04 ) according to analysis of variance. Cherry tomato plants (cultivars L308 and L907) were grown under low EC [LE $\left.\left(2.8 \mathrm{dS} \cdot \mathrm{m}^{-1}\right)\right]$, high EC [HE (4.7 $\left.\left.\mathrm{dS} \cdot \mathrm{m}^{-1}\right)\right]$, or midday reduction of high EC treatment [MDR (midday low EC combined with high EC) $]\left(1 \mathrm{dS} \cdot \mathrm{m}^{-1}=\right.$ $1 \mathrm{mmho} / \mathrm{cm}, 1 \mathrm{~kg}=2.2046 \mathrm{lb})$. and Cuartero, 1993). Reduction in fruit weight from increased EC from 1.4 to $14 \mathrm{dS} \cdot \mathrm{m}^{-1}$ was reported in Alarcon et al. (1994a) in which fruit weight was $50 \%$ to $60 \%$ less in high EC-treated plants than in plants fertigated with a low EC nutrient solution. It seems that $14 \mathrm{dS} \cdot \mathrm{m}^{-1}$ is too high for assuring normal development of tomato fruit.

For 'L907', the cumulative yield of all cherry tomato grades over 15 weeks of harvest for the LE treatment was significantly higher than the $\mathrm{HE}$ treatment but was not significantly different from the MDR treatments (Table 2). A similar trend was observed in the cumulative yield of all grades for 'L308', but there was no significant difference between treatments. Higher yield in the LE treatment for 'L907' was because of the larger fruit weight. The LE treatment was not subjected to water stress as were the other treatments. Therefore, water flux to fruit may have contributed more to increased fruit weight. Adams (1991) showed that yield of tomato was reduced with increasing EC from 3 to 8 or $12 \mathrm{dS} \cdot \mathrm{m}^{-1}$. Sakamoto et al. (1999) also reported similar tomato yield reduction in response to increasing EC from 2.4 to $5 \mathrm{dS} \cdot \mathrm{m}^{-1}$ or from 2.4 to $8 \mathrm{dS} \cdot \mathrm{m}^{-1}$ due to the lower number of fruit and the lower fresh weight at the higher EC. However, in our experiment, fresh weight decreased at a greater extent than did fruit number.

Cultivar $(P=0.01)$ and treatment $(P<0.0001)$ were significant factors affecting the TSS of the cherry tomato fruit harvested (Fig. 2).

Table 2. Cumulative yield (all and premium grades) of cherry tomato fruit for 15 weeks of harvest as affected by cultivar and EC treatment.

\begin{tabular}{lcc}
\hline Treatments $^{\mathbf{z}}$ & $\begin{array}{c}\text { Cumulative yield-all } \\
\text { grades }^{\mathbf{y}}\left(\mathbf{k g} \cdot \mathbf{m}^{-2}\right)^{\mathbf{x}}\end{array}$ & $\begin{array}{c}\text { Cumulative yield-premium } \\
\text { grade }^{\mathbf{y}}\left(\mathbf{k g} \cdot \mathbf{m}^{-2}\right)^{\mathbf{x}}\end{array}$ \\
\hline 'L308' & $24.1^{\mathrm{a}}$ & $17.6^{\mathrm{a}}$ \\
HE & $28.1^{\mathrm{a}}$ & $12.1^{\mathrm{b}}$ \\
LE & $24.9^{\mathrm{a}}$ & $16.2^{\mathrm{a}}$ \\
MDR & & \\
'L907' & $22.1^{\mathrm{B}}$ & $12.9^{\mathrm{A}}$ \\
HE & $26.3^{\mathrm{A}}$ & $1.39^{\mathrm{C}}$ \\
LE & $24.7^{\mathrm{AB}}$ & $11.6^{\mathrm{B}}$ \\
MDR & & 14.7 \\
\hline
\end{tabular}

${ }^{z}$ Cherry tomato plants were grown under low EC $\left[\operatorname{LE}\left(2.8 \mathrm{dS} \cdot \mathrm{m}^{-1}\right)\right]$, high EC $\left[\mathrm{HE}\left(4.7 \mathrm{dS} \cdot \mathrm{m}^{-1}\right)\right]$, or midday reduction of high EC treatment [MDR (midday low EC combined with high EC)], and fruit were harvested for a 15 -week period $\left(1 \mathrm{dS} \cdot \mathrm{m}^{-1}=1 \mathrm{mmho} / \mathrm{cm}\right)$.

y Harvested cherry tomato fruit were graded to Premium and standard grades according to sampled soluble solid concentration of juice, size of the fruit, ripeness stage, and overall visual quality.

${ }^{\mathrm{x}}$ Means within the same column for each cultivar (L907 or L308) followed by the different letters are significantly different from an ANOVA-protected least significant difference test at $P<0.05\left(1 \mathrm{~kg} \cdot \mathrm{m}^{-2}=0.2048 \mathrm{lb} / \mathrm{ft}^{2}\right)$. 

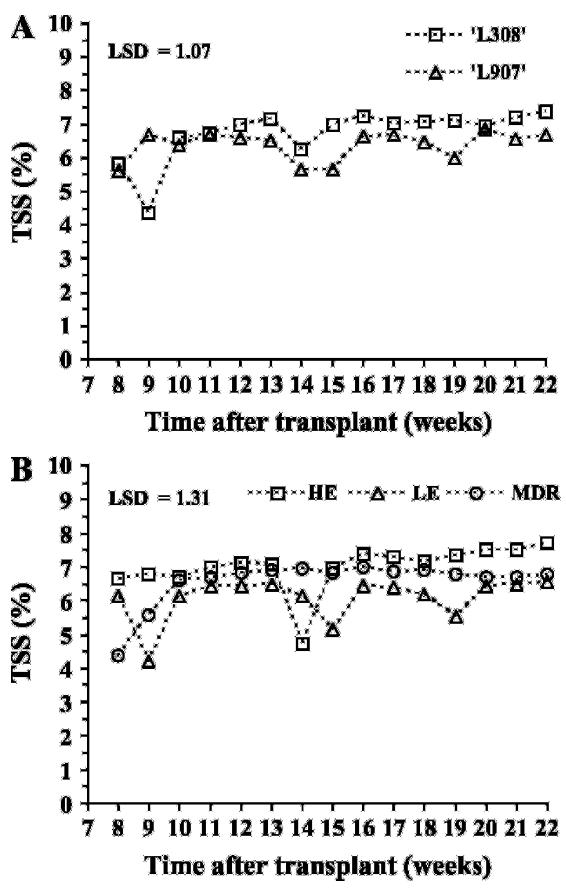

Fig. 2. The TSS of cherry tomato fruit as affected by (A) cultivars L308 and L907 and (B) EC treatment over a 15-week period. The cultivar $\times$ week interaction was significant $(P=\mathbf{0 . 0 1})$ according to analysis of variance. The EC treatment $\times$ week interaction was significant $(P<0.0001)$ according to analysis of variance. Cherry tomato plants were grown under low EC [LE $\left.\left(2.8 \mathrm{dS} \cdot \mathrm{m}^{-1}\right)\right]$, high EC [HE $(4.7$ $\left.\mathrm{dS} \cdot \mathrm{m}^{-1}\right)$ ], or midday reduction of high EC treatment [MDR (midday low EC combined with high EC)], and fruit were harvested over a 15-week period $\left(1 \mathrm{dS} \cdot \mathrm{m}^{-1}=1 \mathrm{mmho} / \mathrm{cm}\right)$.

The low premium yield in the 'L308' LE treatment was because of the low TSS. The lower percentage of premium-grade yield in the MDR treatment was because of relatively large fruit size than the premium quality standard. Reduction of fruit size may have been accomplished by increasing the number of heads per plant from two to three, which may decrease the amount of water flux to fruit, thus decreasing their weight. BER was not observed throughout the experiment.

Cumulative premium yield (Table 2) for the LE treatment was only $12 \%$ and $11 \%$ of those for the MDR and HE treatments, respectively in 'L907'. For 'L308', the cumulative premium yield for the LE treatment was $74 \%$ and $68 \%$ of the MDR and HE treatments, respectively. For 'L308', cumulative premium yield in the MDR treatment
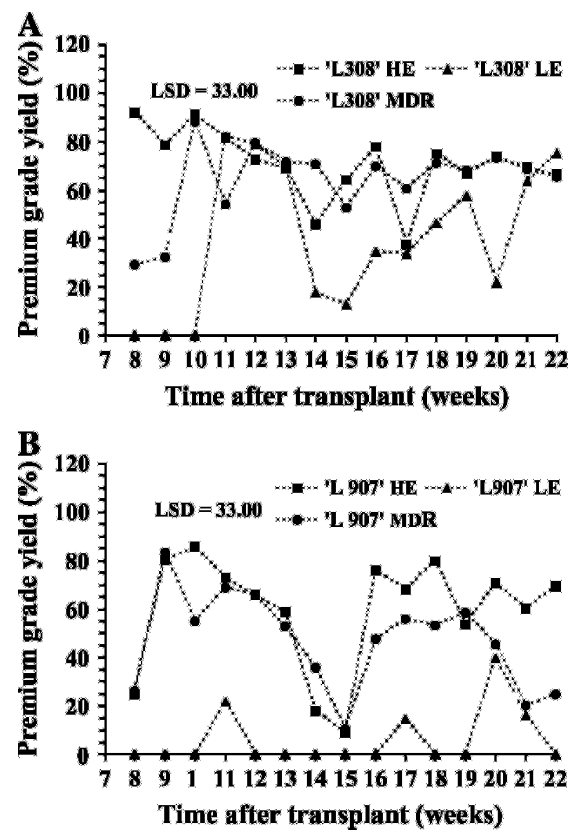

Fig. 3. The percent premium grade yield of cherry tomato fruit over a 15-week period. The cultivar $\times$ EC treatment $\times$ week interaction was significant $(P<0.0001)$ according to analysis of variance. Cherry tomato plants [cultivars L308 (A) and L907 (B)] were grown under low EC [LE $\left.\left(2.8 \mathrm{dS} \cdot \mathrm{m}^{-1}\right)\right]$, high EC [HE $(4.7$ $\left.\left.\mathrm{dS} \cdot \mathrm{m}^{-1}\right)\right]$, or midday reduction of high EC treatment [MDR (midday low EC combined with high EC)], and fruit were harvested over a 15-week period $\left(1 \mathrm{dS} \cdot \mathrm{m}^{-1}=1 \mathrm{mmho} / \mathrm{cm}\right)$.

was not significantly different from that in the HE treatment. Cherry tomatoes of the premium or similar grades (those found as specialty produce department in U.S. supermarkets) are sold at a price two to four times greater than what the U.S. Department of Agriculture (2006) reported for the average retail price of U.S. fresh market tomato in 2005 . Considering this price difference, greenhouse growers could strategically apply high EC to a selected cultivar to increase the TSS and therefore produce more tomatoes falling in premium grades despite the small decrease in the total yield of all grades. Manipulation of EC for enhancing TSS of tomato fruit is a well-practiced technique in the greenhouse; however, economic analysis, including the premium price of high TSS tomatoes, is not available among the available literature. Based on our tomato yield of premium and all grades, it seems that producing more premium-grade tomatoes by sacrificing a small amount of total yield loss may be more profitable than maximizing yields, regardless of fruit quality. Because the percentage of premium grades varied over time, mainly because of seasonal changes in greenhouse microclimates, complete economic analyses are necessary to examine the feasibility of this method.

\section{Conclusions}

'L308' cluster cherry tomato produced higher yields [total and premium-grade yield $\left.\left(\mathrm{kg} \cdot \mathrm{m}^{-2}\right)\right]$ and better fruit quality (i.e., greater TSS) compared with 'L907'. The response to EC variations was strongly affected by cultivar, therefore, cultivar selection should be considered also by growers. The LE treatment in both cultivars produced a relatively high cumulative yield, especially in 'L907', but when quality standards were applied, the LE treatment produced the least amount of premiumgrade cherry tomatoes for both cultivars. The MDR treatment yielded almost the same as the LE treatment for tomatoes of all grades and achieved the premium-grade tomato yield comparable to the HE treatment, which may make this strategy more attractive under semiarid greenhouse with limited controlled-environment technology.

\section{Literature cited}

Adams, P. 1991. Effects of increasing the salinity of the nutrient solution with major nutrients or sodium chloride on the yield, quality and composition of tomato grown in rockwool. J. Hort. Sci. 66:201-207.

Adams, P. and C. Ho. 1989. Effects of constant and fluctuating salinity on the yield, quality and calcium status of tomatoes. J. Hort. Sci. 64:725-732.

Adams, P. and R. Holder. 1992. Effects of humidity, $\mathrm{Ca}$ and salinity on the accumulation of dry-matter and $\mathrm{Ca}$ by the leaves and fruit of tomato (Lycopersicon esculentum). J. Hort. Sci. 67:137-142.

Alarcon, J.J., M.C. Bolarin, M.J. SanchezBlanco, and A. Torrecillas. 1994a. Growth, yield and water relations of normal fruited and cherry tomato cultivars irrigated with saline water. J. Hort. Sci. 69:283-288

Alarcon, J.J., M.J. Sanchez-Blanco, M.C. Bolarin, and A. Torrecillas. 1994b. Growth and osmotic adjustment of two 
Preliminary and Regional Reports

tomato cultivars during and after saline stress. Plant Soil 166:75-82.

Cuartero, J. and R. Fernández-Munoz. 1999. Tomato and salinity. Scientia Hort. 78:83-125.

Dorais, M., A.P. Papadopoulos, and A. Gosselin. 2001. Influence of electric conductivity management on greenhouse tomato yield and fruit quality. Agronomie 21:367-383.

Evans, M.R., S. Konduru, and R.H. Stamps. 1996. Source variation in physical and chemical properties of coconut coir dust. HortScience 31:965-967.

Gonzáles-Fernández, J.J. and J. Cuartero. 1993. Evolución de la producción de cuatro entradas de tomate cultivadas con sal. Actas de Horticultura 10:1067-1072.

Ho, L. and P. Adams. 1989. Effects of diurnal changes in the salinity of the nutrient solution on the accumulation of calcium by tomato fruit. Ann. Bot. (Lond.) 64:373-382.

Jeganathan, M. 1992. Nut water analysis as a diagnostic tool in coconut nutrition studies. Commun. Soil Sci. Plant Anal. 23:2667-2686

Krauss, S., W.H. Schnitzler, J. Grassmann, and M. Woitke. 2006. The influence of different electrical conductivity values in a simplified recirculation soilless system on inner and outer fruit quality characteristics of tomato. J. Agr. Food Chem. 54:441448.

Li, Y.L., C. Stangehellini, and H. Challa. 2001. Effect of electrical conductivity and transpiration on production of greenhouse tomato (Lycopersicon esculentum L.). Scientia Hort. 88:11-29.

Sakamoto, Y., S. Watanabe, T. Nakashima, and K. Okano. 1999. Effects of salinity at two ripening stages on the fruit quality of singe-truss tomato grown in hydroponics. J. Hort. Sci. Biotechnol. 74:690693.

Santamaria, P., V. Cantore, G. Conversa, and F. Serio. 2004. Effect of night salinity level on water use, physiological responses, yield and quality of cherry tomato. J. Hort. Sci. Biotechnol. 79:59-66.

U.S. Department of Agriculture. 2006. Background statistics: Fresh-market tomatoes. 3 Jan. 2008. <http://www.ers. usda.gov/News/tomatocoverage.htm>

van Ieperen, W. 1996. Effects of different day and night salinity levels on vegetative growth, yield and quality of tomato. J. Hort. Sci. 71:99-111.

Wu, M. and C. Kubota. 2008. Effects of electrical conductivity of hydroponic nutrient solution on leaf gas exchange of five greenhouse tomato cultivars. HortTechnology 18:271-277. 